\title{
EL NUEVO DERECHO PENAL DE ADOLESCENTES Y LA NECESARIA REVISIÓN DE SU “TEORÍA DEL DELITO”*
}

\author{
Héctor Hernández Basualto ${ }^{* *}$
}

\begin{abstract}
RESUMEN
El artículo sostiene que, por razones constitucionales y jurídico-internacionales, el Estado de Chile tiene el deber de establecer un régimen penal diferenciado y tendencialmente más benigno para infractores adolescentes, deber que no se agota en el establecimiento de un sistema diferenciado de penas, sino que debe expresarse también en un sistema diferenciado de presupuestos de la responsabilidad penal. En la medida en que la Ley 20.084 sólo se hace cargo expresamente del primer aspecto, corresponde a la dogmática penal formular interpretativamente la "teoría del delito" del derecho penal de adolescentes. Al efecto se ensayan varias posibles adaptaciones del régimen vigente para adultos a la especialidad etaria de los adolescentes, tanto en materia de injusto como de culpabilidad.
\end{abstract}

\section{DERECHO PENAL DE ADOLESCENTES - TRATAMIENTO DIFERENCIADO - TEORÍA DEL DELITO}

\section{The new criminal act and a much necessary revision of the requirements of juvenile criminal liability}

\begin{abstract}
This work propounds that on the grounds of constitutional and international law, the State of Chile is under the obligation to establish a differentiated and essentially more benign juvenile Criminal Justice System. This obligation entails the instauration of a specialised punishment system as well as a differentiated system of requirements of criminal liability. Since Chilean Act $N^{\circ} 20.084$ only deals with the first aspect, it is the scholars' task - brough interpretation - to formulate the "General Part" for Juvenile Criminal Law. Towards this end, the present work tests various potential adaptations of the current system for adults to the juvenile age group, both on the fields of the legal wrong and mens rea.
\end{abstract}

\section{JUVENILE CRIMINAL LAW - DIFFERENTIATED TREATMENT - REQUIREMENTS OF CRIMINAL LIABILITY}

\footnotetext{
* "El artículo tiene su origen en un informe encargado al autor por la Unidad de Defensa Penal Juvenil de la Defensoría Nacional Pública”.

** Abogado, Doctor en Derecho, Profesor de Derecho Penal y Derecho Procesal Penal, Facultad de Derecho Universidad Alberto Hurtado, Cienfuegos 41, Santiago, hhernand@uahurtado.cl Trabajo recibido el 30 de agosto de 2007 y aceptado para su publicación por el Comité Editorial el 22 de octubre de 2007.
} 


\section{LA LEY 20.084 COMO FORMA DE CUMPLIMIENTO DEL DEBER DE ESTABLECER UN RÉGIMEN PENAL DIFERENCIADO PARA ADOLESCENTES}

$\mathrm{M}$ ediante la Ley 20.084, Ley de Responsabilidad Penal de Adolescentes (en adelante LRPA), se ha establecido un nuevo régimen jurídico para el tratamiento de infracciones de ley penal por parte de adolescentes, esto es, menores de edad pero mayores de catorce años (art. $3^{\circ}$ LRPA). Elemento esencial del nuevo modelo superador del esquema tutelar vigente en el país hasta este año es la afirmación sin ambages de una genuina responsabilidad penal de los adolescentes infractores. Se supera así la situación de inimputabilidad absoluta vigente para los menores de dieciséis años y de inimputabilidad relativa -condicionada por el pronunciamiento judicial sobre el "discernimiento" del agente- previsto para los menores de dieciocho años pero mayores de dieciséis (art. $10 \mathrm{~N}^{\text {os. }} 2$ y $3 \mathrm{CP}$, suprimidos por la ley). ${ }^{1}$

Al mismo tiempo, como contrapartida, se establece un régimen penal diferenciado para los adolescentes, tanto en sus aspectos sustantivos como procesales, con garantías equiparables a las que rigen para infractores adultos y caracterizado, en términos generales, por una relativa benignidad en comparación con el régimen penal general. De esta manera, se entiende, el Estado chileno estaría dando cumplimiento a sus compromisos internacionales en orden a asegurar un régimen garantista y moderado de punición de infractores adolescentes, tal como se desprende, fundamentalmente, de la Convención Internacional de Derechos del Niño.

En efecto, los artículos 37 y 40 de la Convención aseguran a los niños imputados de haber infringido la ley penal una serie de garantías fundamentales tanto de carácter material como procesal, en tanto que las notas de necesaria moderación o benignidad se desprenden forzosamente de la conjunción, por una parte, de la exigencia de un régimen penal especial para adolescentes, consagrada en la Convención, ${ }^{2}$ con el objeto y la orientación general de la misma en términos de reforzar el status jurídico de dichos infractores, por la otra. La exigencia del establecimiento de un régimen penal especial en el contexto de la Convención sólo puede tener como sentido que se trate de un régimen favorable - esto es, más benigno y moderado- para quienes no han alcanzado la mayoría de edad.

${ }^{1}$ Una excelente síntesis del régimen legal anterior en Cillero, M., “Artículo 10 Nos. 2 y 3”, en Politoff, S. y Ortiz, L. (directores), Texto y comentario del Código penal chileno, T. I, Editorial Jurídica de Chile, Santiago 2002, pp. 109 y ss.

${ }^{2}$ El art. $40 \mathrm{~N}^{\circ} 3$ de la Convención dispone: "Los Estados Partes tomarán todas las medidas apropiadas para promover el establecimiento de leyes, procedimientos, autoridades e instituciones específicos para los niños de quienes se alegue que han infringido las leyes penales o a quienes se acuse o declare culpables de haber infringido esas leyes...". Por su parte, el art. 37 prohíbe la imposición a los adolescentes de ciertas penas aún admisibles para adultos, como la pena capital, en tanto que a propósito del trato humanitario y digno que se le debe en general a todas las personas impone, además, que en éste "se tengan en cuenta las necesidades de las personas de su edad". 
La diferenciación en términos de relativa moderación o benignidad viene impuesta en consideración a las peculiaridades del agente. ${ }^{3}$ No obstante aceptarse la posibilidad conceptual y práctica de una responsabilidad penal en los adolescentes, al mismo tiempo se reconoce que, por el evidente menor grado de desarrollo y madurez asociado al tramo etario al que pertenecen los mismos, su responsabilidad debe adoptar características y tener alcances diferentes de los que se aceptan respecto de personas adultas. ${ }^{4}$ Desde una elemental y clásica noción de justicia e igualdad ante la ley se impone entonces el deber de un tratamiento diferenciado sobre la base de una situación reconocidamente diferente.

El aspecto que más evidentemente se vincula con esta constatación es, desde luego, el de las consecuencias jurídicas del delito, esto es, el del sistema de penas previstas para las infracciones cometidas por adolescentes. En este contexto parece imperativa la consideración de un régimen penal menos estricto que el que rige para adultos, en un doble sentido: por una parte, en términos absolutos, cuando se trata de penas equiparables a las tradicionales para adultos, mediante la alteración de los marcos penales abstractos y con límites máximos de su extensión en el caso concreto; por la otra, en términos relativos, con la previsión de un abanico de posibilidades punitivas como alternativa efectiva frente a dichas sanciones tradicionales. ${ }^{5}$ Ambos sentidos se encuentran nítidamente expresados en el nuevo texto legal.

En lo que concierne a lo primero, la modificación hacia la baja de los marcos penales aplicables en comparación con lo que rige para adultos se consagra en el art. 21 LRPA, en cuanto prevé que la determinación de las penas aplicables al adolescente deba hacerse "a partir de la pena inferior en un grado al mínimo de los señalados por la ley para el ilícito correspondiente". ${ }^{6}$ Adicionalmente deben considerarse los límites máximos de pena establecidos en el art. 18 LRPA, conforme al cual "las penas de internación en régimen cerrado y semicerrado, ambas con programa de reinserción social, que se impongan a los

${ }^{3}$ En el Preámbulo de la Convención se lee: "Recordando que en la Declaración Universal de Derechos Humanos las Naciones Unidas proclamaron que la infancia tiene derecho a cuidados y asistencia especiales", a lo que se agrega: "Teniendo presente que la necesidad de proporcionar al niño una protección especial ha sido enunciada en la Declaración de Ginebra de 1924 sobre los Derechos del Niño y en la Declaración de los Derechos del Niño adoptada por la Asamblea General el 20 de noviembre de 1959, y reconocida en la Declaración Universal de Derechos Humanos, en el Pacto Internacional de Derechos Civiles y Políticos (en particular, en los artículos 23 y 24), en el Pacto Internacional de Derechos Económicos, Sociales y Culturales (en particular, en el artículo 10) y en los estatutos e instrumentos pertinentes de los organismos especializados y de las organizaciones internacionales que se interesan en el bienestar del niño”.

${ }^{4}$ Sobre los aportes de la psicología actual a la fundamentación de una capacidad disminuida de autodeterminación en los adolescentes. Vid. Martín Cruz, A., Los fundamentos de la capacidad de culpabilidad penal por razón de la edad, Comares, Granada 2004, pp. 157 y ss.

${ }^{5}$ El No 4 del art. 40 de la Convención dispone: "Se dispondrá de diversas medidas, tales como el cuidado, las órdenes de orientación y supervisión, el asesoramiento, la libertad vigilada, la colocación en hogares de guarda, los programas de enseñanza y formación profesional, así como otras posibilidades alternativas a la internación en instituciones, para asegurar que los niños sean tratados de manera apropiada para su bienestar y que guarde proporción tanto con sus circunstancias como con la infracción”.

${ }^{6}$ Redacción dada por la Ley 20.191, de 2 de junio de 2007. 
adolescentes no podrán exceder de cinco años si el infractor tuviere menos de dieciséis años, o de diez años si tuviere más de esa edad”. Sin perjuicio de la legítima discusión en cuanto a si con este sistema el legislador chileno realmente ha estado a la altura del espíritu de los compromisos internacionales en cuanto a establecer un régimen realmente moderado de punición, no puede al menos negarse que, en efecto, el rango de punibilidad previsto para los adolescentes es inferior al que rige para los infractores adultos.

En lo que dice relación con el segundo aspecto, tampoco puede negarse, más allá de las críticas que pueda merecer el diseño concreto, que se ha establecido un régimen diferenciado de sanciones, que prevé variadas alternativas a la privación de libertad, como son la libertad asistida especial, la libertad asistida, la prestación de servicios en beneficio de la comunidad, la reparación del daño causado, la multa y la amonestación (art. $6^{\circ}$ LRPA). $^{7}$

Con esto se puede decir que, más allá de las legítimas críticas que se le puedan dirigir al resultado del proceso legislativo, el Estado chileno ha establecido un sistema diferenciado de tratamiento penal para los adolescentes, al menos en lo que concierne al sistema de penas.

\section{LA DIFERENCIACIÓN NO ABORDADA EXPLÍCITAMENTE POR LA LEY: ¿INTERPRETACIÓN O IMPUGNACIÓN?}

Ocurre, sin embargo, que existe un amplio grupo de cuestiones esenciales en materia de responsabilidad penal que no han sido abordadas explícitamente por la ley, y respecto de las cuales también debería regir el deber de un tratamiento diferenciado. Tal es el caso del conjunto de los presupuestos de la responsabilidad penal y, al mismo tiempo, de las causas de exención de la misma, esto es, lo que podría denominarse la teoría del delito del derecho penal de adolescentes. A este respecto puede afirmarse que el establecimiento de un régimen diferenciado de responsabilidad penal tiene todavía una importante tarea pendiente, en cuanto a que, al no haber sido abordados estos aspectos por el legislador, queda obligado el intérprete a una lectura diferenciada de las reglas generales sobre la materia cuando éstas deben ser aplicadas a infractores adolescentes.

No basta entonces con un régimen de sanciones diferenciado y más benigno, pues también las reglas de adjudicación de responsabilidad penal deben hacerse cargo y respetar el menor grado de desarrollo objetivo -reconocido como tal por el ordenamiento internacional- presente en el infractor. Y no basta porque la ley sólo se ha hecho cargo del quantum de la pena, no del si de la misma, abriendo la posibilidad de imponer una sanción penal, por benigna que ésta sea, a partir de la aplicación de una vara diseñada para medir la conducta de sujetos con un grado de madurez diferente, en circunstancias

${ }^{7}$ Sin perjuicio del lamentable retroceso que significó la inconsulta modificación del art. 23 en orden a establecer como pena única la internación en régimen cerrado para el primer tramo previsto en ese artículo, propiciada por el Senador Hernán Larraín a instancias del Ministro de Justicia Carlos Maldonado. 
que de aplicarse la vara adecuada, proporcionada a las características del sujeto, podría resultar que no debiera imponerse ninguna sanción. Se trata, en consecuencia, de una tarea ineludible.

De lo contrario no sólo se deja sin cumplimiento una obligación internacional, sino que, en cuanto no se distingue entre situaciones diferentes, se termina consagrando un sistema desigual, desproporcionado e injusto, vulnerando de ese modo al menos la garantía de igualdad ante la ley consagrada en el art. $19 \mathrm{~N}^{\circ} 2 \mathrm{CPR}$. Es por esto último que no puede ser de recibo el posible argumento en cuanto a que el legislador, al no prever modificaciones, adoptó la decisión soberana de aplicar el mismo régimen de presupuestos de la responsabilidad penal que rige para los adultos también a los adolescentes. Más bien al contrario, no habiendo declaración expresa de parte del legislador en orden a consagrar un régimen difícilmente conciliable con el ordenamiento constitucional e internacional, se impone por fuerza la conclusión de que el legislador ha preferido dejar en manos del intérprete el desarrollo de las matizaciones requeridas por las reglas generales para llegar a un sistema efectivamente diferenciado de responsabilidad penal para adolescentes.

Ahora bien, contra lo que se viene sosteniendo y que constituye presupuesto del desarrollo de las páginas siguientes, podría sostenerse que las deficiencias de la ley en este punto no pueden subsanarse por vía interpretativa, de modo que sólo quedaría impugnar su legitimidad. Específicamente podría sostenerse que la ley, en cuanto no considera un régimen distinto del que rige para adultos en materia de presupuestos de responsabilidad, contraviene tanto la citada garantía de igualdad ante la ley reconocida en el art. $19 \mathrm{~N}^{\circ} 2$ CPR, como los citados artículos 37 y 40 de la Convención de Derechos del Niño, Convención que, en cuanto inequívoco instrumento internacional en materia de Derechos Humanos debería entenderse incorporada al derecho chileno con rango constitucional, de acuerdo con una extendida interpretación del art. $5^{\circ}$ inciso segundo CPR que aquí se comparte ${ }^{8}$ y que ha sido acogida al menos de modo tácito en un fallo reciente del Tribunal Constitucional, que ha versado precisamente sobre la compatibilidad de la LRPA con la Convención. ${ }^{9}$ Correspondería, en consecuencia, instar por su inaplicabilidad e inconstitucionalidad ante el Tribunal Constitucional (art. 93 $\mathrm{N}^{\circ} 6$ y $\mathrm{N}^{\circ} 7$ CPR).

Esta solución radical no parece, sin embargo, necesaria. Nótese que no se pone en duda su corrección intrínseca, sino sólo su necesidad, toda vez que la vía interpretativa ofrece una solución suficientemente satisfactoria. Sin poner en duda la vigencia de un

${ }^{8}$ Al respecto, entre otros, Verdugo, M., Pfeffer, E. y Nogueira, H., Derecho constitucional, T. I, Editorial Jurídica de Chile, Santiago 2002, pp. 126 y ss.

${ }^{9}$ Sentencia de 13 de junio de 2007, en causa Rol 786-2007. En efecto, ante un requerimiento que en lo fundamental alegaba que la modificación al art. 23 LRPA debida a la aprobación de la moción LarraínMaldonado contravenía el art. $5^{\circ}$ inciso segundo CPR por ser incompatible con la Convención, el Tribunal aceptó entrar derechamente al análisis de la compatibilidad de la mencionada modificación con el instrumento internacional, confirmando de ese modo, más allá de la valoración que pueda merecer el resultado concreto, el rango constitucional del mismo en virtud del citado art. $5^{\circ}$ inciso segundo (Considerandos $26^{\circ}$ a $28^{\circ}$ ). 
control concentrado de constitucionalidad de las leyes en el derecho chileno, tampoco puede dudarse el deber general de los órganos del Estado y, en particular, de los tribunales, de someter su actuación a la Constitución. Específicamente en el ámbito de la jurisdicción esto implica el deber de todo juez de realizar una interpretación conforme a la Constitución, es decir, el deber de preferir, dentro de las posibilidades interpretativas que admite la letra de la ley, aquellas lecturas que sean compatibles con el texto constitucional. El límite está dado, naturalmente, por las posibilidades interpretativas. Allí donde el sentido de la ley es inequívocamente contrario a la Constitución ya no puede hablarse de "interpretación” cuando se quieren eludir sus consecuencias. En esos casos sólo cabe constatar la incompatibilidad de la ley con la Carta Fundamental y procurar que se active el mecanismo de control represivo de constitucionalidad de las leyes, concentrado hoy en el Tribunal Constitucional.

Si bien se ve, el camino de la interpretación conforme a la Constitución se encuentra considerablemente abierto en el contexto de la LRPA, en la medida en que la ley no contiene ninguna disposición que explícita y categóricamente se oponga a una interpretación diferenciada de los presupuestos de la responsabilidad penal de los adolescentes. El silencio que puede reprochársele al texto legal es al mismo tiempo el contexto que permite una interpretación ajustada a los designios constitucionales. Por otra parte, precisamente esta posibilidad de una interpretación conforme a la Constitución reduce las posibilidades de una impugnación exitosa de la constitucionalidad de la ley, no porque se niegue la corrección de la objeción, sino sólo porque, en virtud de los principios de deferencia razonada y de presunción de constitucionalidad de las leyes, el Tribunal Constitucional debería entender que el sentido de la ley es precisamente aquél que resulta compatible con la Carta Fundamental, afirmando su constitucionalidad, a menudo "en el entendido" de que se respete esa interpretación, a través de una sentencia interpretativa. ${ }^{10} \mathrm{Si}$ a esto se agrega la tradicional -y universal- parquedad de los textos legales en cuanto a los presupuestos de la responsabilidad penal y la consiguiente relevancia de la construcción dogmática en la materia, expresada fundamentalmente a través de la llamada "teoría del delito", no debería causar extrañeza que la realización del programa constitucional e internacional relativo al tratamiento penal de los adolescentes infractores de ley deba corresponder en gran medida al trabajo metódico y sistemático del intérprete.

Premisa central de este trabajo es, en consecuencia, que el imperativo de establecer un régimen diferenciado de presupuestos de responsabilidad en el derecho penal de adolescentes no se encuentra íntegramente satisfecho con la sola promulgación de la LRPA sino que está en buena medida pendiente, correspondiéndole a los tribunales de justicia, a través de una interpretación conforme a la Constitución, terminar con la tarea.

Más precisamente, la LRPA sólo vino a zanjar una de las cuestiones por resolver, como era la determinación de la edad a partir de la cual se es, en principio, penalmente

${ }^{10}$ Al respecto Zapata, P., La jurisprudencia del Tribunal Constitucional, Universidad Andrés Bello, Santiago 2002, pp. 69 y ss. (deferencia razonada), 79 y ss. (presunción de constitucionalidad), 120 y ss. (sentencias interpretativas). 
imputable. ${ }^{11}$ Como es obvio, sin embargo, ése es sólo uno de los factores en juego, referido exclusivamente a la inimputabilidad por inmadurez o escaso desarrollo. De ahora en adelante no será posible discutir desde cuándo un adolescente se considera en principio imputable, pero no se ha resuelto nada respecto de las demás exigencias de la punibilidad, tanto las que dicen relación con el injusto (tipicidad, antijuridicidad) como con las restantes categorías que deben considerarse en el examen de culpabilidad. Si la premisa es correcta, también respecto de estas categorías es un imperativo de proporcionalidad y, en su virtud, de igualdad ante la ley, hacer las adecuaciones a la llamada "teoría del delito" que sean necesarias para asegurar un tratamiento penal justo para los adolescentes.

\section{EXCURSO: ANTECEDENTES EN LA DOGMÁTICA PENAL GENERAL}

El desafío recuerda en alguna medida los esfuerzos que deben hacerse en la dogmática penal general para impedir que la constatación de la inimputabilidad exima ilegítimamente del irrenunciable análisis exhaustivo de los presupuestos de la punibilidad, con todas sus injustas secuelas. En efecto, sin que deban llegar a abrazarse las propuestas sistemáticas de Maurach ${ }^{12}$ en cuanto a reconocer la categoría de la "responsabilidad por el hecho" o "atribuibilidad", no puede sino aceptarse que la inimputabilidad del agente no exime de la previa verificación en la especie no sólo de una conducta típica y antijurídica atribuible al mismo, sino que, además, de una conducta cuya abstención habría sido también exigible a una persona plenamente imputable, con lo cual se asegura que ningún inimputable que incurra en un hecho con características de delito pueda ser sometido a medidas de seguridad o corrección por el solo hecho de ser inimputable, en circunstancias que por el mismo hecho el imputable sería absuelto sin más. ${ }^{13}$

Sólo que este caso no se trata de exigir la verificación de los presupuestos de la responsabilidad penal más allá de la imputabilidad in puncto madurez. En la medida en

${ }^{11}$ La letra a) del $\mathrm{N}^{\circ} 3$ del ya citado art. 40 de la Convención prescribe el "establecimiento de una edad mínima antes de la cual se presumirá que los niños no tienen capacidad para infringir las leyes penales”.

${ }^{12}$ Maurach, R. y Zipf, H., Derecho penal. Parte general 1 (trad. Bofill y Aimone), Astrea, Buenos Aires 1994, pp. 535 y ss.; en el ámbito hispanoamericano Jiménez de Asúa, L., Tratado de derecho penal, Losada, Buenos Aires 1970, T. V, No 1473 y ss. y más recientemente Bacigalupo, E., Manual de derecho penal. Parte general, Temis, Bogotá 1989, pp. 138 y ss.

${ }^{13}$ En contra, entre nosotros, Cury, E., Derecho penal. Parte general, $7^{\text {a }}$ edición, Ediciones Universidad Católica de Chile, Santiago 2005, p. 407: "cabe imaginar que un enfermo mental cometa un delito a consecuencia de tendencias precipitadas por la dolencia, pero que, por pura casualidad, lo haga en circunstancias excluyentes de la exigibilidad... En estos casos la imposición de una 'reclusión' en establecimiento psiquiátrico parece justificada, aunque no se den los presupuestos para exigir otra conducta, incluso a un hombre normal". Por esta vía, sin embargo, en la medida en que se emancipa la imposición de la medida de seguridad de las restantes exigencias de la responsabilidad penal, en rigor se legitiman verdaderas medidas predelictuales o sin delito, sin contar con que de hecho se aplanan todas las dificultades probatorias y se presume sin más que la posible situación de inexigibilidad es "pura casualidad” y que aun en circunstancias normales e inimputables hubiera incurrido en el hecho típico y antijurídico. 
que el carácter de adolescente no excluye la responsabilidad penal, ya no es necesario enfatizar esa exigencia. Pero si el carácter de adolescente condiciona la especialidad de dicha responsabilidad penal, de lo que se trata en este contexto es de establecer los términos en que se expresa tal especialidad.

\section{Consecuencias en materia de injusto típico}

\section{Limites generales a la aplicabilidad de ciertas descripciones típicas}

La LRPA no establece un catálogo separado de conductas punibles. Si se prescinde de la exclusión que se hace en el art. $1^{\circ}$ de la mayoría de las faltas, ${ }^{14}$ en general constituyen hechos punibles también para el derecho penal de adolescentes los mismos hechos que lo son en el derecho penal de adultos.

Esto no significa, sin embargo, que no puedan hacerse ciertas matizaciones tratándose de hechos cuya criminalización, cuando son cometidos por menores de edad, no sólo no parece racional ni conveniente, sino que, además, y esto es lo decisivo, manifiestamente no responde a los propósitos legislativos, porque resulta evidente que al formular el respectivo tipo penal el legislador ha tenido en mente sólo la comisión por parte de un adulto, al punto que dicha circunstancia es esencial para el sentido criminal del hecho.

Los casos más nítidos dicen relación con delitos en los cuales la víctima sólo puede ser un niño o adolescente, circunstancia que algunas veces sólo adquiere relevancia en contraste con la calidad de adulto del agente o, al menos, en atención a una significativa diferencia de edad. Es lo que ocurre, por ejemplo, con el delito de violación impropia del art. 362 CP o, más aún, con el de abusos sexuales impropios del art. 366 bis CP, cuya racionalidad es directamente proporcional a la diferencia de edad que media entre los sujetos involucrados. Pues, en efecto, la criminalización de las acciones sexuales que recíprocamente se prodigan dos "pololos" adolescentes cuando uno de ellos tiene trece y el otro quince sería a todas luces grotesca. Esto se hizo notar críticamente a propósito de la desafortunada reforma de los delitos sexuales debida a la Ley 19.927, de 14 de enero de $2004,{ }^{15}$ crítica que si bien no tuvo efecto en ese contexto, sí fue recogida por el art. $4^{\circ}$ de la LRPA, del siguiente tenor:

"No podrá procederse penalmente respecto de los delitos previstos en los artículos 362, 365, 366 bis y 366 quater del Código Penal, cuando la conducta se hubiere realizado con una persona menor de 14 años y no concurra ninguna de las circunstancias enumeradas en los artículos 361 o 363 de dicho Código, según sea el caso,

${ }^{14} \mathrm{Y}$ eventualmente de los cuasidelitos, de acuerdo con una posible interpretación.

${ }^{15}$ Al respecto Hernández, H., "El derecho penal chileno en el cambio de siglo", en Persona y Sociedad, Universidad Alberto Hurtado, Vol. XVIII, N 2 (2004), p. 213 (pp. 227 y ss.). 
a menos que exista entre aquélla y el imputado una diferencia de, a lo menos, dos años de edad, tratándose de la conducta descrita en el artículo 362, o de tres años en los demás casos". ${ }^{16}$

Si bien las expresiones empleadas por la ley no son del todo claras en cuanto a la calificación sistemática de la exclusión de la punibilidad, es evidente que no se trata de una simple renuncia al castigo por razones de conveniencia, sino que del reconocimiento del fundamento del mismo, de modo que debe entenderse que el tipo objetivo de los delitos en cuestión exige la diferencia de edad que en cada caso se indica. De este modo, el legislador reconoce abiertamente que la edad del agente es un aspecto central para la configuración típica de algunos delitos, lo que, sin embargo, había permanecido oculto hasta ahora en el contexto del derecho penal de adultos, porque, en efecto, alcanzada la adultez el dato etario pierde toda su importancia.

Ahora bien, como es evidente, la norma se hace cargo exclusivamente de la situación advertida a propósito de ciertos delitos sexuales, respecto de los cuales la aplicación lisa y llana del tipo penal sin consideración a la edad del imputado conduciría a resultados completamente irracionales. No debe despreciarse, sin embargo, su potencial hermenéutico más allá de los límites de su tenor literal. La norma encierra un razonamiento que debería aplicarse a una serie de otros supuestos delictivos, tales como, por sólo mencionar algunos relativamente evidentes, los siguientes:

Todavía en el ámbito de los delitos sexuales, la previsión del citado art. $4^{\circ}$ se queda corta en la detección de hipótesis problemáticas. Piénsese, por ejemplo, en la producción de material pornográfico, prevista en el art. 366 quinquies $\mathrm{CP}$, y su potencial aplicación respecto de la pareja de adolescentes que filman sus contactos sexuales; ${ }^{17}$ o en la facilitación de la prostitución infantil de acuerdo con el art. 367 bis CP tratándose de dos amigas que, para obtener dinero, se turnan para favorecer la prostitución de la otra, entre otros posibles casos. Todo indica que estas conductas no corresponden en absoluto a las representaciones que tuvo el legislador a la hora de establecer las conductas típicas, nítidamente orientadas hacia la explotación sexual de los adolescentes por parte de adultos o, eventualmente, de menores de edad respecto de los cuales la diferencia etaria sea significativa.

En materia de sustracción de menores (art. 142 CP), conforme a la opinión ampliamente dominante, realiza la conducta típica el que, tratándose de niños menores de 10 años, los determina a abandonar su hogar. ${ }^{18}$ Esta interpretación es esencialmente correcta y se hace cargo tanto de la circunstancia de que los niños pequeños carecen de la suficiente autonomía ambulatoria como para que se pueda imputar a su voluntad el

\footnotetext{
${ }^{16} \mathrm{La}$ norma expresa lo que en el derecho norteamericano se ha dado en llamar la "Romeo and Juliet defense", especialmente discutida a propósito del fallo estadual "Wilson v. State of Georgia" (2006).

${ }^{17}$ Puede ocurrir que sólo uno de ellos realice la conducta típica, pero perfectamente puede ser que ambos incurran en ella.

${ }^{18}$ Por todos, Etcheberry, A., Derecho penal, $3^{\text {a }}$ edición, Editorial Jurídica de Chile, Santiago 1998, T. III, pp. 212 y ss.
} 
abandono del hogar, con lo cual puede seguir hablándose de una "sustracción”, y al mismo tiempo es coherente con lo prescrito en el art. $357 \mathrm{CP}$, en cuanto a que la inducción a un menor de edad pero mayor de diez años al abandono del hogar es un delito diferente, con una pena considerablemente menor. Ahora bien, esta corrección y razonabilidad se desvanecen cuando se considera el caso, por ejemplo, de un niño de catorce o quince años que decide abandonar su hogar $y$, en ese contexto, convence a su vecino de nueve años para que lo acompañe. También en este caso, como es evidente, la situación no corresponde de modo alguno a lo que razonablemente han sido las representaciones del legislador. Tanto o más evidente es la misma conclusión cuando se piensa en la aplicación del mencionado delito de inducción al abandono de hogar al adolescente que convence a otro -que incluso podría ser mayor que él- de acompañarlo en sus aventuras.

En casos como éstos se deben reconocer necesariamente superados los límites de sentido del tipo en cuestión y se impone una reducción teleológica del tenor literal del mismo, en el sentido de aceptar un elemento tácito del tipo, como es que el sujeto activo sea mayor de edad o al menos supere en edad a la víctima en una medida tal que su conducta pueda considerarse abusiva de esa circunstancia. ${ }^{19}$

El fundamento de la reducción teleológica no descansa, por cierto, en una mera referencia a las posibles representaciones del legislador, como tal vez podrían sugerir las explicaciones precedentes. Como es obvio, no porque éste haya tenido en mente formas más o menos convencionales de matar a la hora de tipificar el delito de homicidio deben excluirse del tipo las muertes provocadas empleando métodos inusuales. Por el contrario, lo que realmente importa no es la representación, sino el fin de protección que se colige del contexto del proceso legislativo y del sistema de la misma ley.

Para lo que importa en este trabajo, la especial consideración de la minoría de edad de la víctima sugiere también ciertas características del autor del delito. A todas luces la ley quiere proteger a una determinada categoría de personas que considera vulnerables frente a sujetos que se encuentran en situación de abusar de dicha vulnerabilidad, que son precisamente quienes no pertenecen a la misma categoría. Así, por ejemplo, si se mira con detenimiento la discusión legislativa en materia de delitos sexuales, lo que se quiere reprimir en primera línea no es la sexualidad de los menores de edad sino el abuso o explotación de que son víctimas los mismos, abuso que está ineludiblemente asociado a la superioridad etaria del autor. Lo mismo ocurre en materia de sustracción de menores, donde manifiestamente no se quiere proteger a los niños o adolescentes de sí mismos, sino que de una amenaza que viene de personas mayores. Nótese que cuando dos menores de edad abandonan su hogar para la ley ambos están perdidos y necesitados de protección, de modo que mal puede decirse que por el único hecho de haber dado lugar a la decisión del otro, uno es víctima y el otro victimario, a menos, claro está, que se caiga en una inaceptable distinción entre niños tendencialmente honestos (víctimas)

${ }^{19}$ Es posible que respecto de algunos delitos la restricción teleológica deba ir incluso más allá de la consideración de la edad del agente, como parece obvio respecto del delito de producción de material pornográfico infantil (que filmaciones íntimas sin propósito de difusión realicen el tipo a todo evento es sin duda un exceso), pero no es algo que se pueda abordar en este contexto. 
y niños tendencialmente deshonestos (victimarios), que la ley ciertamente no ha podido avalar. Todo indica que la finalidad de la ley es proteger a los menores fundamentalmente de los mayores. En consecuencia y a menos que en la especie concurran circunstancias abusivas, tratándose de relaciones entre niños y adolescentes sin una diferencia significativa de edad, la ley no ha querido extender a ellas las respectivas figuras típicas. Si no hizo distinciones fue porque éstas eran en general innecesarias en el contexto de una responsabilidad penal muy acotada de los menores de edad. En el nuevo escenario legislativo, en cambio, corresponde hacerlas al intérprete.

No está de más recordar que la reducción teleológica es un procedimiento normal en la interpretación del derecho en general y del derecho penal en particular. Que una interpretación razonable debe tener presente el telos de la ley, en términos de atribuirle a los preceptos un alcance coherente con el mismo, en tanto no se oponga frontalmente a la letra del texto, es, en rigor, algo indiscutible. Un buen ejemplo de este proceder lo ofrece la propia interpretación del art. $142 \mathrm{CP}$ en cuanto al sujeto activo del delito. No obstante que la ley no hace ningún distingo, se ha impuesto sin contrapeso la interpretación que excluye del círculo de posibles autores a los padres del niño o adolescente, aunque no lo tengan a su cargo, toda vez que se ha entendido que la ratio legis del precepto abarca sólo hipótesis de riesgo para el menor provenientes de personas ajenas a su entorno. ${ }^{20} \mathrm{Nada}$ distinto es lo que se propone para la interpretación de los tipos penales que tienen por víctima específica a menores de edad en el contexto del derecho penal de adolescentes.

En el peor de los casos debería imponerse la aplicación analógica in bonam partem del art. $4^{\circ}$ LRPA, aplicación de analogía que, en cuanto favorece al reo y expresa coherentemente la inequívoca valoración legislativa, debería contar con respaldo mayoritario. ${ }^{21}$

Cuál habrá de ser, en uno u otro caso, la específica diferencia de edad entre sujeto activo y sujeto pasivo a partir de la cual sí puede entenderse realizado el respectivo tipo penal, es una cuestión discutible que debe ser objeto de análisis particular respecto de cada figura típica. Como sea, debería servir de orientación general el criterio expresado en el art. $4^{\circ}$ LRPA.

\section{Exclusiones particulares del injusto}

Adicionalmente debe considerarse que durante la adolescencia, por la inmadurez del sujeto, por la relativa inestabilidad emocional que marca la etapa y por las peculiares formas de sociabilidad que se desarrollan en la misma, es natural que las percepciones sean diferentes de las que rigen entre los adultos, lo que necesariamente tiene influencia en la

${ }^{20}$ Así Etcheberry, T. III, p. 212; Politoff, S., Matus, J. P. y Ramírez, M. C., Lecciones de derecho penal chileno. Parte especial, $2^{a}$ edición, Editorial Jurídica de Chile, Santiago 2005, p. 211. Véase también sentencia de la Corte de Apelaciones de Santiago de 12 de septiembre de 1990, en Revista de Derecho y Jurisprudencia, T. LXXXVII, 2-4, pp. 137 y ss.

${ }^{21}$ Como se sabe, la analogía in bonam partem se admite mayoritariamente entre nosotros. Véase, por todos, Cury, $P G$, pp. 202 y ss. 
cognición y asimilación de conceptos que se construyen necesariamente en forma social, muchos de los cuales estructuran los tipos penales. En este contexto es perfectamente imaginable que se produzca un desfase entre la percepción que el adolescente tiene del significado del entorno y de sus propios actos y la que el resto de la población puede tener, desfase que debe ser reconocido y valorado por el sistema jurídico-penal.

Ejemplos nítidos de lo anterior se obtienen cuando se observan las singulares formas de interacción que suelen darse entre adolescentes, especialmente en ciertos contextos. La relativa brutalidad y falta de consideración que a veces ostentan tales formas de contacto, unida a su fuerte expresión corporal, permitirían la subsunción del comportamiento en tipos penales tales como los de lesiones, amenazas o daños, entre otros. Y desde luego tal tipicidad no puede excluirse a priori, porque es perfectamente posible - no es otra cosa lo que justifica la existencia de la ley-que los adolescentes cometan esos delitos. Lo que interesa destacar en este contexto es simplemente que en estos casos se impone siempre el deber de comprobar que en el caso concreto en efecto se trata de un comportamiento con el significado propio del respectivo título delictivo y no de una situación normal -aunque extraña y molesta- de interacción torpe, etariamente condicionada.

Cuando tales formas de interacción ostenten un grado tal de difusión y relativa aceptación que permita verlas como conductas normales y sin connotación delictiva, puede derechamente negarse su tipicidad de la mano de la vieja doctrina welzeliana de la adecuación social, ${ }^{22}$ la que, sin perjuicio de su progresiva superación en el contexto de la teoría de la imputación objetiva in puncto imputación de resultados y colaboración en el injusto ajeno, ${ }^{23}$ mantiene inalterado su potencial hermenéutico respecto de los alcances de la conducta típica en cuanto tal, sin consideración a sus ulteriores consecuencias. Así, por ejemplo, tal como los pequeños presentes de cortesía que se le hacen a un funcionario público o las privaciones mínimas de libertad derivadas de la forma de prestar un servicio no realizan, por ser conductas socialmente adecuadas, los respectivos tipos penales de cohecho activo (art. 250 CP) o de secuestro (art. $141 \mathrm{CP}$ ), tampoco deberían considerarse típicas conductas juveniles que son comprendidas y aceptadas como normales en el entorno social en que se insertan. La posible objeción en cuanto a que de esta manera se introduce una variable de vaguedad o indeterminación en la interpretación de la ley, pasaría por alto que el recurso a valoraciones sociales sectoriales es un método irrenunciable de la dogmática penal. Nada distinto es lo que se hace para

${ }^{22}$ Al respecto Welzel, H., "Studien zum System des Strafrechts", ZStW 58 (1939), p. 491 (citado de Welzel, H., Abhandlungen zum Strafrecht und zur Rechtsphilosophie, Walter de Gruyter, Berlin - New York 1975 , pp. 120 y ss. [p. 142 y ss.]; hay versión castellana: "Estudios sobre el sistema de derecho penal" [trad. Aboso y Löw], en Welzel, H., Estudios de derecho penal, Bdef, Montevideo 2002, pp. 15 y ss. [pp. 50 y ss.]); y Welzel, H., Derecho penal alemán (trad. Bustos y Yáñez, parcial, de la $11^{\text {a }}$ y última edición alemana de 1969), Editorial Jurídica de Chile, Santiago 1970, pp. 83 y ss.

${ }^{23}$ Al respecto, entre muchos otros, Jakobs, G., "La prohibición de regreso en los delitos de resultado" (trad. Cancio Meliá), en Jakobs, H., Estudios de derecho penal, Civitas, Madrid 1997, p. 244. 
determinar la existencia de un engaño concluyente en la estafa ${ }^{24}$ o los alcances del deber de cuidado en los delitos culposos. ${ }^{25}$

Como sea, con independencia del reconocimiento de esta realidad en el seno del tipo objetivo, al menos debería asegurársele un espacio en el ámbito del tipo subjetivo, concretamente a través del llamado error de tipo. Esto último será posible cuando la diferente percepción no condicione ya sólo una divergencia de valoración con el sistema jurídico (campo propio del error de prohibición, como más abajo se expresa), sino que además un déficit cognitivo que afecta la comprensión de las circunstancias que rodean la propia conducta. Y así es como la posibilidad de un error de tipo condicionado precisamente por la inmadurez e inexperiencia del adolescente imputado ha sido pacíficamente reconocida en la práctica de otros ordenamientos jurídicos, como ocurre, por ejemplo, en la aplicación práctica del derecho alemán. ${ }^{26}$

Esto no debería extrañar si se consideran, a la luz de la menor madurez del adolescente, los términos de la discusión general en torno al dolo y a su opuesto que es el error de tipo, en particular en lo que dice relación con la forma y grado de "conocimiento" exigido por el primer elemento de este binomio. Como se sabe, al respecto predomina una postura a medio camino entre la exigencia extrema de cuanto menos que conciencia "reflexiva" de la concurrencia de los elementos del tipo en la propia conducta y la simple prescindencia del elemento cognoscitivo a su respecto. En general se admite, a partir de diversos enfoques psicológicos, que para el "conocimiento" exigido por el dolo basta con que los elementos del tipo objetivo se encuentren al menos implícitamente contenidos ("mitbewußt") en aquello de lo que se tiene explícita conciencia. ${ }^{27}$ Pues bien, para que pueda ser afirmada esta conciencia implícita se requiere un importante grado de internalización de los significados concurrentes, ${ }^{28}$ que es, sin embargo, precisamente lo que puede faltar en el adolescente por su menor grado de desarrollo. Como se puede apreciar, se abre un importante campo de discusión sobre si el adolescente ha podido percibir las notas fundamentales que definen el significado de su conducta.

Algo similar cabe decir en materia de antijuridicidad, contexto en el cual también se imponen adecuaciones en razón de la edad del imputado. En este ámbito, el campo más fructífero en esta dirección lo representa la interpretación diferenciada de los requisitos de las causas de justificación principales, como son la legítima defensa (art. 10 $\mathrm{N}^{\text {os. }} 4$ a $6 \mathrm{CP}$ ) y el estado de necesidad (art. $10 \mathrm{~N}^{\circ} 7 \mathrm{CP}$ ). Con todo, no puede negarse

${ }^{24}$ Al respecto Hernández, H., “Aproximación a la problemática de la estafa”, en AA. VV., Problemas actuales de derecho penal, Universidad Católica de Temuco, Temuco 2003, pp. 164 y ss.

${ }^{25} \mathrm{Al}$ respecto, entre muchos otros, Bustos, J., El delito culposo, Editorial Jurídica de Chile, Santiago 1995 , pp. 47 y ss.

${ }^{26}$ Así Albrecht, P. - A., Jugendstrafrecht, 2. Aufl., Beck, München 1993, p. 101 (hay versión castellana de la primera edición: El derecho penal de menores [trad. Bustos], PPU, Barcelona 1990).

${ }^{27} \mathrm{Al}$ respecto, con cierto detalle y referencia a los trabajos de Platzgummer, Schmidhäuser y Schewe, entre otros, Roxin, C., Strafrecht. Allgemeiner Teil I, 4. Aufl., Beck, München 2006, § 12 Rdn. 122 y ss. (hay versión castellana de la segunda edición: Derecho penal. Parte general [trad. Luzón Peña, Díaz y García Conlledo y De Vicente Remesal], Civitas, Madrid 1997).

${ }^{28}$ Roxin, AT I, § 12 Rdn. 128. 
que probablemente el cauce natural para esta diferenciación sea el de la culpabilidad, como se expresa tradicionalmente a través del reconocimiento del llamado exceso en la legítima defensa como eventual hipótesis a ser tratada bajo el signo de la inexigibilidad de otra conducta. Sobre esto se vuelve más abajo.

\section{Consecuencias pendientes en materia de Culpabilidad}

Probablemente el campo más fértil para distinciones respecto del derecho penal de adultos sea el de la culpabilidad. Como se ha dicho, la Ley $\mathrm{N}^{\circ} 20.084$ sólo se hace cargo de la inimputabilidad y, más específicamente, sólo de la cuestión de la inimputabilidad por minoría de edad, restando entonces la interpretación y adecuación de los demás presupuestos de la categoría.

\section{En materia de inimputabilidad}

Comenzando por la inimputabilidad misma, en este contexto, parece evidente que la inimputabilidad por enfermedad mental debe sufrir una profunda revisión, estableciéndose un modelo de análisis atento y respetuoso de la singularidad del estado en cuestión cuando se presenta en un individuo que es, además, adolescente. La inmadurez y labilidad del sujeto, su relativa inestabilidad emocional y, consecuentemente, la posibilidad de reacciones irracionales propias de una etapa de transición vital obliga a atribuirle un peso considerablemente mayor a alteraciones mentales que, tratándose de adultos, no parecen tan significativas. ${ }^{29}$

En el caso del derecho chileno esto es apenas discutible, pues es la propia legislación la que se ha encargado de afirmar la especial consideración que merecen las anomalías mentales que sufren los adolescentes. Es lo que se desprende inequívocamente de la actual regulación del delito de estupro, consistente en el acceso carnal a personas menores de edad pero mayores de catorce años mediando, entre otras hipótesis, la circunstancia de abuso de "una anomalía o perturbación mental, aun transitoria, de la víctima, que por su menor entidad no sea constitutiva de enajenación o transtorno” (art. 363 No $1 \mathrm{CP}$ ).

Como se sabe, el acceso carnal a personas mayores de catorce años mediante abuso de su "enajenación o transtorno mental" constituye siempre delito, cualquiera que sea la edad de la víctima (específicamente el delito de violación, art. 361 No 3 CP), en tanto

${ }^{29} \mathrm{La}$ existencia de alteraciones mentales condicionadas o potenciadas por el insuficiente grado de desarrollo del sujeto es algo que, por ejemplo, se reconoce ampliamente en el derecho alemán, sistema en el que la distinción entre éstas y otras posibles alteraciones independientes de la edad tiene la mayor importancia práctica porque, si bien en ambos casos se exime de responsabilidad penal, las demás consecuencias jurídicas (posible imposición de medidas de seguridad) se rigen por normas diferentes, al respecto Lenckner, T. y Perron, W., en Schönke/Schröder, Strafgesetzbuch. Kommentar, 27. Aufl., Beck, München 2006, § 20 Rdn. 44; Albrecht, Jugendstrafrecht, p. 102. Con todo, la vara con que se mide la situación de inimputabilidad parece ser la misma, aspecto que debería ser distinto en el derecho chileno, según se argumenta en el texto. 
que el abuso de una simple anomalía o perturbación mental, la que, por definición, tal como recalca la ley, no tiene la entidad suficiente como para constituir enajenación o transtorno, tiene relevancia penal sólo en casos excepcionales, precisamente cuando la víctima es adolescente. Así, mientras el acceso carnal a una persona de treinta años que padece una anomalía mental no constituye delito aun cuando se haya abusado de esa circunstancia, la decisión legal es radicalmente diferente cuando la víctima es menor de edad, aunque la anomalía sea equiparable. Lo mismo rige respecto de la realización de acciones sexuales distintas del acceso carnal y su encuadramiento en el tipo de abusos sexuales (arts. 366 inciso segundo, 365 bis $\mathrm{N}^{\circ} 3 \mathrm{CP}$ ).

Con esto el legislador está expresando, sin margen alguno para dudas, que en su valoración una anomalía o perturbación mental, aunque sea de menor entidad, tiene una significación diferente, de mayor gravedad, cuando se trata de personas que, además, no han alcanzado la edad en que, en términos generales, se alcanza la madurez. En otras palabras, la minoría de edad como factor adicional concomitante a la anomalía o perturbación hace de esta última un estado relativamente equivalente al de la enajenación o transtorno tratándose de adultos. ${ }^{30}$

Las consecuencias de esta valoración para la determinación de los alcances del art. $10 \mathrm{~N}^{\circ} 1 \mathrm{CP}$ aplicado a infractores adolescentes parecen indiscutibles. Si bien el criterio se ha expresado sólo respecto de un grupo de delitos, en la medida en que no se ve contradicho por otras decisiones legislativas puede asignársele validez general. Por otro lado, aunque se haya empleado explícitamente sólo para definir el umbral de protección de las víctimas de tales delitos, es evidente que debe traspasarse coherentemente también a la situación de los potenciales infractores, en la medida en que se trata de valoraciones que comparten exactamente el mismo sustrato, cual es el estado mental del sujeto, pasivo en un caso, activo en el otro. Si tratándose de víctimas adolescentes el umbral de protección se eleva de la mano de una reducción de las exigencias en cuanto a la gravedad que debe presentar la alteración mental para darle relevancia penal a su aprovechamiento, tratándose de infractores adolescentes debe necesariamente darse la misma reducción de tales exigencias, en este caso para los efectos de la exención de responsabilidad penal. Cualquier otra interpretación implicaría no ya sólo desconocer en general las peculiaridades del desarrollo de los adolescentes, con la consecuente imposición de un tratamiento desproporcionadamente severo, sino que, además, una abierta discriminación entre grupos de adolescentes. Naturalmente el ordenamiento jurídico no puede amparar que respecto de un aspecto común a todos los adolescentes como es su inmadurez se distinga entre adolescentes "buenos" y "malos", prodigando en base a ese factor mayor protección a los primeros, y simplemente ignorándolo en relación con los segundos.

${ }^{30}$ Sólo relativamente equivalente, pues de todas maneras el legislador tiende a valorar de un modo diferente ambas situaciones, como se expresa en la mayor penalidad que ostenta la violación frente al estupro, sin perjuicio de que en la actual regulación del delito de abusos sexuales no se haga ninguna diferencia. 
Ahora bien, con el objeto de evitar posibles malentendidos, aquí no se está planteando que para los efectos del art. $10 \mathrm{~N}^{\circ} 1 \mathrm{CP}$ en el derecho penal de adolescentes se deba interpretar la "locura o demencia" como "anomalía o perturbación mental" en los términos del art. 363 N $^{\circ} 1 \mathrm{CP}$. En esa medida, no es necesario tratar de demostrar en este contexto si aquel primer concepto se corresponde o no exactamente con el de "enajenación o trastorno mental" del art. $361 \mathrm{~N}^{\circ} 3 \mathrm{CP}$, si bien eso es lo que parece desprenderse de la revisión de nuestra literatura jurídico-penal al respecto. ${ }^{31}$ Aunque así fuera, como ya se ha dicho, la equiparación valorativa entre enajenación o trastorno y anomalía o perturbación no se da en términos absolutos ni aun en el ámbito de los delitos sexuales. Lo que se trata de demostrar es, más bien, que las perturbaciones mentales tienen en nuestro derecho, desde antes de la Ley $\mathrm{N}^{\circ} 20.084$, una relevancia mayor cuando afectan a los adolescentes, lo que necesariamente debe expresarse en la interpretación del art. $10 \mathrm{~N}^{\circ} 1$ $\mathrm{CP}$ cuando se aplica precisamente a adolescentes. No en términos de que -para volver a recalcarlo- cualquier anomalía o perturbación del rango de aquéllas que son relevantes en materia de estupro deba dar lugar a la exención de responsabilidad penal, pero sí en cuanto a que la "locura o demencia" debe afirmarse ya con una anomalía relevante, por mucho que no alcance la entidad que, conforme a la jurisprudencia general al respecto, rige para estos fines cuando se trata de infractores adultos.

Cuando la anomalía o perturbación mental no alcanza una entidad tal que, ni aun aplicando el criterio que se viene proponiendo, permita afirmar la exención de la responsabilidad del adolescente, ésta de todos modos tiene relevancia, a menos que sea insignificante, como "imputabilidad disminuida", tanto en cuanto circunstancia atenuante (eximente incompleta del art. $11 \mathrm{~N}^{\circ} 1 \mathrm{CP}$ en relación con el art. $10 \mathrm{~N}^{\circ} 1$ $\mathrm{CP})$ como, antes incluso, en cuanto posible factor de inexigibilidad. Ambos aspectos se abordan más adelante.

\section{En materia de inexigibilidad de otra conducta}

Algo similar a lo desarrollado en el acápite anterior cabe decir de la principal fuente para el tratamiento de la llamada inexigibilidad de otra conducta entre nosotros, como

${ }^{31}$ Así, respecto de la regulación legal vigente hasta 1999, Etcheberry, T. IV, p. 60 (mujeres "dementes”); Labatut, G., Derecho penal. T. II, $7^{\text {a }}$ edición (a cargo de Julio Zenteno), Editorial Jurídica de Chile, Santiago 1983, p. 139 ("enajenación mental”, sus matices están referidos al inciso segundo del art. 10 No 1 CP); Garrido, M., Derecho penal, T. III, 2a edición, Editorial Jurídica de Chile, Santiago 2005, p. 291 (en esta parte se reproducen las explicaciones de la primera edición [1998], referidas a la ley vigente hasta 1999). En la literatura posterior, Cox, J. P., Los abusos sexuales. Aproximación dogmática, Lexis-Nexis, Santiago 2003 , pp. 158 y ss. Lamentablemente no se pronuncian (si bien porque no era obligatorio hacerlo) Rodríguez Collao, L., Delitos sexuales, Editorial Jurídica de Chile, Santiago 2000, pp. 155 y ss.; Politoff, Matus y Ramírez, PE, pp. 259 y ss.; Bullemore, V. y Mackinnon, J., Curso de derecho penal, Lexis-Nexis, Santiago 2005, T. III, p. 187, si bien puede colegirse el mismo criterio. En contra sólo Maldonado, F., "Delitos contra la libertad sexual”, en VV. AA., Problemas actuales de derecho penal, pp. 249 y ss.; y ahora Garrido, T. III, pp. 365 y ss. (en la parte referida a la nueva situación legal, a cargo precisamente de Maldonado), aunque no parece que de la tajante distinción que se pretende entre ambos conceptos se sigan consecuencias significativas en cuanto a la gravedad requerida en uno y otro caso, que es lo que importa en el contexto de este trabajo. 
es la circunstancia eximente de fuerza irresistible o miedo insuperable, prevista en el art. $10 \mathrm{~N}^{\circ} 9 \mathrm{CP}$.

Una primera aproximación intuitiva al respecto podría encontrar sustento en la tendencia creciente entre nosotros hacia la aplicación de lo que se ha dado en llamar un criterio individualizador a la hora de evaluar la inexigibilidad de otra conducta, criterio conforme al cual la aplicación de la eximente de fuerza irresistible o miedo insuperable en el caso concreto supone considerar no sólo el carácter extraordinario de las circunstancias concomitantes, sino que también evaluar el efecto de las mismas desde la perspectiva de las particularidades personales de quien se ve enfrentado a ellas. ${ }^{32}$ Pues, se dice, lo que puede atemorizar hasta el punto de anular la capacidad de comportamiento conforme a derecho de una persona débil y sin experiencia puede no ser suficiente para lograr el mismo efecto en una persona vigorosa y experimentada.

Este criterio ha encontrado también importante acogida en la interpretación de figuras delictivas particulares, especialmente en relación con los efectos que sobre la víctima ha de tener la circunstancia típica de intimidación, exigida en varios tipos penales, como ocurre con el robo con violencia o intimidación (arts. 433, 436 inciso primero CP) o con la violación o los abusos sexuales (arts. 361 y 366 CP), en particular cuando se discute la verosimilitud de la amenaza, tal como lo exige el concepto. Especialmente en este contexto se ha destacado que el concepto de intimidación típicamente relevante está condicionado por las características de la víctima, y que las exigencias son menores tratándose de víctimas "débiles" que de otras a cuyo respecto se puede presumir un menor grado de susceptibilidad. ${ }^{33}$ Si todo esto fuera correcto, exactamente lo mismo habría de reconocerse, ya desde la dogmática penal general, a la hora de evaluar la aplicación de la circunstancia eximente a los adolescentes imputados de la comisión de un delito. En ese contexto la única importancia de enfatizar la peculiaridad de los adolescentes radicaría en que de ese modo se asegurara con carácter general un examen diferenciado para los infractores adolescentes, obligatoriamente atento al factor etario.

Ahora bien, por plausible que pueda resultar esta primera aproximación, lo que interesa recalcar en este contexto es que la nueva situación legislativa permite arribar a consecuencias semejantes incluso sin necesidad de asumir un criterio individualizador que dista de ser pacífico tanto en el derecho comparado como especialmente entre nosotros. En efecto, en la medida en que lo que se ha configurado es un derecho penal especial para una categoría completa de personas que tienen en común un menor grado de madurez, aun con un criterio generalizador, basado en la idea de las facultades de un

${ }^{32}$ Así, decididamente, Mera, J., Derechos Humanos en el derecho penal chileno, ConoSur, Santiago 1998, pp. 171 y ss.; Náquira, J., “Artículo 10 N 9”, en Politoff, S. y Ortiz, L. (directores), Texto y comentario, pp. 148 y ss.; Politoff, S., Matus, J. P. y Ramírez, M. C., Lecciones de derecho penal chileno. Parte general, Editorial Jurídica de Chile, Santiago 2004, pp. 339 y ss., 343, 347. Con todo, la referencia a las posibilidades del "hombre medio" goza de importante adhesión, al respecto, por todos, Cury, $P G$, p. 457.

33 Así, en materia de violación o abusos sexuales Labatut, T. II, p. 138; Garrido, T. III, pp. 290, 361; Rodríguez Collao, Delitos sexuales, p. 152; Politoff, Matus y Ramírez, PE, pp. 253 y ss. En materia de robo con intimidación Politoff, Matus y Ramírez, PE, pp. 363 y ss. 
"hombre medio", esta idea debería adaptarse a la nota característica de la categoría de sujetos a la que debe aplicarse. En otras palabras, la exigibilidad o inexigibilidad de otra conducta en este ámbito, o más precisamente, el carácter irresistible o insuperable de la fuerza o el miedo que afecta al sujeto debe establecerse al menos a partir de la idea de un "adolescente medio" que, precisamente en razón de su menor desarrollo y madurez, posee en general un potencial menor de exigibilidad. La aplicación del derecho penal de adolescentes no puede desconocer este aspecto.

En el mismo orden de cosas, debe considerarse también la situación especial del exceso en la legítima defensa. Si existe un potencial transitorio de reacciones irracionales y desmedidas, que se explican por una especial sensibilidad y susceptibilidad que definen el grado de desarrollo del adolescente, esto debe considerarse también a la hora de ver en tal exceso la manifestación de una hipótesis de inexigibilidad de otra conducta, en los términos recogidos en el art. $10 \mathrm{~N}^{\circ} 9 \mathrm{CP}^{34}$

Por último, debe abordarse en esta sede la situación de la llamada "imputabilidad disminuida”. Si se admite, como parece correcto, que bajo este rótulo se esconde una situación de exigibilidad disminuida en razón de una anomalía o perturbación mental no despreciable, debería admitirse también que dicha situación puede considerarse derechamente como una de inexigibilidad cuando en el caso concreto concurren otras circunstancias concomitantes extraordinarias que la refuerzan. ${ }^{35}$ De este modo, la imputabilidad disminuida y las aludidas circunstancias extraordinarias no sólo darían lugar por separado a sendas circunstancias atenuantes, sino que permitirían configurar conjuntamente la eximente de fuerza irresistible.

\section{En materia de error de probibición}

En materia de error, como ya se sugirió, ciertas diferencias en cuanto a percepción pueden incluso fundar la aceptación de un error de tipo, cuando la diferencia implica un déficit cognitivo en cuanto al significado objetivo del propio comportamiento. Ahora bien, mientras esa conclusión puede resultar dudosa, es mucho más plausible capturar esos casos por la vía del llamado error de prohibición, esto es, afirmando que por una diferente percepción del significado social del hecho, en términos de valoración social del mismo, el adolescente no ha podido razonablemente conocer el carácter injusto de su conducta ni, consecuentemente, enderezarla de acuerdo con el derecho. Siendo efectivamente así, esto es, tratándose de una imposibilidad invencible para el sujeto concreto, debe eximírsele de responsabilidad, conforme a la jurisprudencia de la Corte Suprema que desde 1998 reconoce el efecto eximente del error de prohibición invencible, efecto

\footnotetext{
${ }^{34}$ Sobre el exceso en la legítima defensa como eventual hipótesis de fuerza irresistible o miedo insuperable, por todos, Cury, $P G$, p. 468.

${ }^{35}$ Así, convincentemente Cury, PG, p. 420.
} 
que funda en la prohibición constitucional de presumir de derecho la responsabilidad penal establecida en el art. $19 \mathrm{~N}^{\circ} 3$ inciso sexto CPR. ${ }^{36}$

Lo que en rigor debe destacarse en este contexto es que, también aquí, al examen normal propio de la dogmática general debe agregársele la consideración del componente etario. En la medida en que la capacidad de internalización de normas en general, y de las normas jurídico-penales en particular, está fuertemente condicionada por los avances del proceso de socialización y, en último término, por el desarrollo del sujeto, no puede dudarse en cuanto a que la exigibilidad de conocimiento del injusto es genéricamente menor tratándose de adolescentes o, dicho en otros términos, que la invencibilidad del error de prohibición es mayor respecto de este grupo. Naturalmente el examen debe practicarse en cada caso en relación con el sujeto que concretamente ha infringido la norma, pero la vara de medición debe ser una genéricamente más baja que la que rige respecto de adultos.

Se podrá apreciar que este razonamiento guarda cierta similitud con el concepto de "error de comprensión" desarrollado por Zaffaroni para un "error" fundado en una diversa comprensión de la realidad condicionada culturalmente. ${ }^{37}$ En este caso, la diversa comprensión estaría condicionada por el menor grado de desarrollo y madurez, si bien no específico del adolescente infractor, sino que común a la categoría de sujetos a la que pertenece y que define el ámbito de aplicación del derecho penal de adolescentes.

\section{CONSECUENCIAS EN EL SISTEMA DE CIRCUNSTANCIAS ATENUANTES Y AGRAVANTES}

Las conclusiones a las que se ha arribado a lo largo de los acápites anteriores pueden y deben proyectarse también a la interpretación en el seno del derecho penal de adolescentes de las circunstancias modificatorias de la responsabilidad penal. No está de más recordar que la determinación de los alcances de estas circunstancias puede ser de la mayor importancia práctica, toda vez que, como se sabe, éstas también inciden en la determinación de la pena del adolescente. En efecto, conforme al art. 21 LRPA, "para establecer la duración de la sanción que deba imponerse con arreglo a la presente ley, el

\footnotetext{
${ }^{36}$ El giro se da con dos importantes sentencias de la Sala Penal de Corte Suprema, de 4 de agosto de 1998 (Gaceta Jurídica No 218 [1998], p. 96) y de 23 de marzo de 1999 (Fallos del Mes No 484 [1999], p. 187). Al respecto Soto Piñeiro, M., "Una jurisprudencia histórica: hacia el reconocimiento del "principio de culpabilidad' en el derecho penal chileno”, Revista de Derecho, Universidad Finis Terrae No 3 (1999), p. 233; Cury, E., "Algunas consideraciones sobre el error de prohibición a la luz de la ley positiva chilena”, en Jaén Vallejo, M. (director), Sistemas penales iberoamericanos. Libro homenaje al Prof. Dr. D. Enrique Bacigalupo en su 65 aniversario, ARA, Lima 2003, p. 719; Cury, PG, p. 447. Una síntesis de los argumentos desarrollados en Chile para fundar el rango constitucional del principio de culpabilidad en Hernández, H., "El régimen de la autointoxicación plena en el derecho penal chileno: deuda pendiente con el principio de culpabilidad", Revista de Estudios de la Justicia, Universidad de Chile, No 9 (2007), p. 11 (pp. 18 y ss.).

${ }^{37}$ Zaffaroni, E. R., Alagia, A. y Slokar, A., Derecho penal. Parte general, Ediar, Buenos Aires 2000, p. 704 .
} 
tribunal deberá aplicar... las reglas previstas en el Párrafo 4 del Título III del Libro I del Código Penal, con excepción de lo dispuesto en el artículo 69 de dicho Código”, con lo cual debe proceder a determinar un rango inicial de pena considerando, entre otros, las circunstancias atenuantes y agravantes previstas genérica o específicamente en la ley.

Como la LRPA no establece circunstancias modificatorias específicas, debe atenderse a las circunstancias generales, las establecidas en los arts. 11 a $13 \mathrm{CP}$, en otros pasajes del Código punitivo o en leyes penales especiales.

Lo primero que resulta preceptivo en este contexto es la extensión de las conclusiones a que se ha arribado en los acápites precedentes, especialmente el referido a la culpabilidad, a las circunstancias atenuantes que, de algún modo, comparten el fundamento de una eximente, pero sin llegar a configurarla, ni aun con las matizaciones que se han propuesto en este trabajo.

Desde luego esto rige en primera línea para la llamada "eximente incompleta" del art. $11 \mathrm{~N}^{0} 1$ CP. Así, en relación con el art. $10 \mathrm{~N}^{\circ} 1 \mathrm{CP}$, si se puede comprobar una anomalía o perturbación mental cuya entidad no alcanza a configurar una "locura o demencia" en los términos de la eximente, ni aun con la vara diferenciada de gravedad impuesta por el principio de proporcionalidad y propiciada en este trabajo, y si tampoco en conjunción con las demás circunstancias del caso da lugar a una hipótesis de inexigibilidad de otra conducta, debería al menos reconocerse la concurrencia de esta circunstancia atenuante (la llamada "imputabilidad disminuida"), siempre y cuando, por cierto, no se trate de una anomalía insignificante, tanto por sus efectos como por su amplia presencia en la población y en todo grupo etario.

Por otra parte, sea en relación con la eximente de fuerza irresistible o miedo insuperable del art. $10 \mathrm{~N}^{\circ} 9 \mathrm{CP}$ o directamente por la vía de atenuantes previstas en el art. $11 \mathrm{CP}$, particularmente las de los $\mathrm{N}^{\circ} 3$ ("haber precedido inmediatamente de parte del ofendido, provocación o amenaza proporcionada al delito"), $\mathrm{N}^{\circ} 4$ ("haberse ejecutado el hecho en vindicación próxima de una ofensa grave causada al autor, a su cónyuge, a sus parientes...") o $\mathrm{N}^{0} 5$ ("obrar por estímulos tan poderosos que naturalmente hayan producido arrebato y obcecación”), debe concedérsele efecto atenuante a contextos que han precipitado reacciones irracionales por parte de un adolescente. Como se dijo a propósito del exceso en la legítima defensa, la inmadurez del adolescente condiciona la aparición de reacciones irracionales, algunas veces violentas, que no pueden entenderse sin consideración a su situación etaria.

También en este punto, en consecuencia, más que insistir en lo que ya con la dogmática penal general se puede lograr a la hora de analizar el caso concreto, se trata de hacer un recordatorio al sistema de justicia criminal en cuanto a que, tratándose de actos imputados a adolescentes, ese análisis debe hacerse con una vara diferente, en razón del principio de proporcionalidad.

En cuanto a las circunstancias agravantes, la singularidad de la situación del agente impone también una revisión cuidadosa de los presupuestos bajo los cuales éstas pueden tener aplicación en el derecho penal de adolescentes. En esta materia debe tenerse muy presente la diferente percepción que respecto de diversas situaciones puede tener un adolescente en comparación con un adulto. Varias de las circunstancias agravantes su- 
ponen una determinada percepción y valoración que, tratándose de personas con una socialización deficiente, probablemente no esté presente. En estos casos, que en el ámbito del derecho penal de adolescentes deberían ser especialmente frecuentes, todo indica que la agravante no debe surtir efecto.

Tal es el caso, por ejemplo, de la circunstancia de "emplear medios o hacer que concurran circunstancias que añadan la ignominia a los efectos propios del hecho" (art. 12 $\mathrm{N}^{\circ} 9 \mathrm{CP}$ ), de aquélla de "ejecutarlo en desprecio o con ofensa de la autoridad pública o en el lugar en que se halle ejerciendo sus funciones" (art. $12 \mathrm{~N}^{\circ} 13 \mathrm{CP}$ ), la de "cometer el delito en lugar destinado al ejercicio de un culto permitido en la República” (art. 12 $\mathrm{N}^{\circ} 17 \mathrm{CP}$ ) o la de "ejecutar el hecho con ofensa o desprecio del respeto que por la dignidad, autoridad, edad o sexo mereciere el ofendido, o en su morada, cuando él no haya provocado el suceso" (art. $12 \mathrm{~N}^{\circ} 18 \mathrm{CP}$ ).

Si bien algunas de estas circunstancias están establecidas en términos objetivos, no puede negarse racionalmente que lo que se reprocha con mayor severidad es precisamente una actitud subjetiva de desprecio por ciertos valores que trascienden al disvalor propio de la comisión delictiva y que tienen nítidamente un referente cultural de cierto nivel de sofisticación, como se expresa en las ideas de "ignominia", "autoridad" o "dignidad", ineludiblemente asociadas a un proceso de socialización e internalización de valores que en el caso de adolescentes no está terminado, de modo que faltarían las bases cognitivas y, con ello, de legitimación de un tratamiento penal más severo. Se trata simplemente de proyectar al ámbito de las circunstancias agravantes las conclusiones extraídas en materia de error -tanto de tipo como de prohibición- respecto de la realización de las conductas incriminadas, como contrapartida de las exigencias positivas de la responsabilidad penal de los adolescentes.

Desde luego también los adultos pueden encontrarse en una situación similar. A su respecto, sin embargo, no obstante ese déficit, se ha estado dispuesto en general a presumir el grado suficiente de socialización. En el caso de los adolescentes, en cambio, los compromisos internacionales del Estado de Chile impiden desconocer este dato esencial fundante del sistema de responsabilidad penal juvenil. Por tanto, tales agravantes no deben surtir efecto.

\section{CONSIDERACIONES FINALES: LA HORA DE LA DOGMÁtiCA PENAL}

A riesgo de resultar trivial, debe insistirse en que el efecto más relevante de la LRPA es la consagración de un genuino derecho penal para adolescentes, con lo que deberían disiparse de una vez todos los eufemismos y ambigüedades que han lastrado tradicionalmente el tratamiento de los adolescentes infractores de la ley penal. Siendo esto así, ya no hay espacio para consideraciones extrajurídicas - por bienintencionadas que éstas pudieran ser- a la hora de resolver sobre la responsabilidad penal de un adolescente. Lo que ahora se impone es la aplicación técnicamente fundada y coherente del derecho penal, aplicación que puede y debe ser objeto de análisis crítico a partir de los criterios de racionalidad propios de la dogmática penal. Se puede afirmar entonces que 
para el tratamiento jurídico de los adolescentes ha llegado, por primera vez en nuestra historia, la hora de la dogmática penal.

Las consecuencias de lo anterior tienen, como todo, aspectos positivos o negativos según el punto de vista. Desde luego se deberían cerrar ciertos espacios para soluciones "justas" sin fundamento, supuestamente legitimadas por su orientación benéfica para el adolescente en la situación concreta. Pero ése parece ser el precio obligado por la superación de los eufemismos y por la consiguiente superación de una práctica judicial oscura, más cercana a una asistencia social de orientación variable -un "no-derecho" - que a la aplicación controlable del derecho. Y, habiendo penas de por medio, esto último es lo único que parece aceptable: derecho penal con todo su rigor, pero a la vez con todas sus garantías y controles. 38

Con este recordatorio se quiere disipar cualquier duda sobre el propósito y el sentido de las páginas precedentes. Lo último que se ha querido hacer es una exhortación sentimental a tratar con bondad a los adolescentes infractores. Muy por el contrario, se ha querido demostrar, con base internacional y constitucional, el deber jurídico de un tratamiento penal diferenciado y tendencialmente más benigno que el que rige para infractores adultos, así como desarrollar siquiera prospectivamente las consecuencias interpretativas que de ese deber habrían de derivarse para la aplicación del derecho penal en todo aquello no modificado en forma expresa por la LRPA. En síntesis, se han querido esbozar las líneas maestras de una dogmática, de una "teoría del delito" diferenciada para los adolescentes, respondiendo así al aludido deber jurídico de diferenciación. Como todo trabajo prospectivo, no pretende de ningún modo conclusiones definitivas, sino sólo inaugurar un espacio de debate - dogmático, cabe reiterarlo- que resulta inaplazable en el nuevo escenario legislativo.

Concretamente, lo que se quiere transmitir a los operadores del sistema penal es que en la lectura y aplicación del Código Penal o de leyes penales especiales a infractores adolescentes no deben considerar sólo las normas de la LRPA que modifican la penalidad de las conductas, sino que también las modificaciones que en materia de afirmación de responsabilidad penal se derivan de la particular situación etaria del imputado.

\section{BIBLIOGRAFÍA}

Albrecht, P.-A., Jugendstrafrecht, 2. Aufl., Beck, München, 1993.

Bacigalupo, E., Manual de derecho penal. Parte general, Temis, Bogotá, 1989.

Bullemore, V., Mackinnon, J., Curso de derecho penal, Lexis-Nexis, Santiago, 2005.

Bustos, J., El delito culposo, Editorial Jurídica de Chile, Santiago, 1995.

Cillero, M., “Artículo 10 Nos. 2 y 3”, en Politoff, S. y Ortiz, L. (directores), Texto y comentario del Código penal chileno, T. I, Editorial Jurídica de Chile, Santiago, 2002.

Cox, J. P., Los abusos sexuales. Aproximación dogmática, Lexis-Nexis, Santiago, 2003.

${ }^{38}$ En ese sentido debe aplaudirse que la idea de tribunales penales integrados por jueces de familia no haya prosperado en la tramitación legislativa. 
Cury, E., "Algunas consideraciones sobre el error de prohibición a la luz de la ley positiva chilena”, en JAÉn VALlejo, M. (director), Sistemas penales iberoamericanos. Libro homenaje al Prof. Dr. D. Enrique Bacigalupo en su 65 aniversario, ARA, Lima, 2003.

Cury, E., Derecho penal. Parte general, $7^{a}$ edición, Ediciones Universidad Católica de Chile, Santiago, 2005.

Etcheberry, A., Derecho penal, $3^{a}$ edición, Editorial Jurídica de Chile, Santiago, 1998.

Garrido, M., Derecho penal, T. III, 2 a edición, Editorial Jurídica de Chile, Santiago, 2005.

Hernández, H., "Aproximación a la problemática de la estafa", en AA. VV., Problemas actuales de derecho penal, Universidad Católica de Temuco, Temuco, 2003.

Hernández, H., "El derecho penal chileno en el cambio de siglo", en Persona y Sociedad, Universidad Alberto Hurtado, Vol. XVIII, No 2 (2004), p. 213.

Hernández, H., "El régimen de la autointoxicación plena en el derecho penal chileno: deuda pendiente con el principio de culpabilidad”, en Revista de Estudios de la Justicia, Universidad de Chile, No 9 (2007), p. 11.

Jakobs, G., "La prohibición de regreso en los delitos de resultado" (trad. Cancio Meliá), en Jakobs, G., Estudios de derecho penal, Civitas, Madrid, 1997.

Jiménez de Asúa, L., Tratado de derecho penal, Losada, Buenos Aires, 1970.

Labatut, G., Derecho penal, T. II, $7^{a}$ edición (a cargo de Julio Zenteno), Editorial Jurídica de Chile, Santiago, 1983.

Maldonado, F., "Delitos contra la libertad sexual", en VV. AA., Problemas actuales de derecho penal, Universidad Católica de Temuco, Temuco, 2003.

Martín Cruz, A., Los fundamentos de la capacidad de culpabilidad penal por razón de la edad, Comares, Granada, 2004.

Maurach, R. y Zipf, H., Derecho penal. Parte general 1 (trad. Bofill y Aimone), Astrea, Buenos Aires, 1994.

Mera, J., Derechos Humanos en el derecho penal chileno, ConoSur, Santiago, 1998.

NÁquira, J., “Artículo $10 \mathrm{~N}^{\circ}$ 9”, en Politoff, S. y Ortiz, L. (directores), Texto y comentario del Código penal chileno, T. I, Editorial Jurídica de Chile, Santiago, 2002.

Politoff, S., Matus, J. P. y Ramírez, M. C., Lecciones de derecho penal chileno. Parte general, Editorial Jurídica de Chile, Santiago, 2004.

Politoff, S., Matus, J. P. y Ramírez, M. C., Lecciones de derecho penal chileno. Parte especial, $2^{a}$ edición, Editorial Jurídica de Chile, Santiago, 2005

Rodríguez Collao, L., Delitos sexuales, Editorial Jurídica de Chile, Santiago, 2000.

Roxin, C., Strafrecht. Allgemeiner Teil I, 4. Aufl., Beck, München, 2006.

SchÖnke/SchröDER, Strafgesetzbuch. Kommentar, 27. Aufl., Beck, München, 2006.

Soto Piñeiro, M., "Una jurisprudencia histórica: hacia el reconocimiento del "principio de culpabilidad' en el derecho penal chileno", en Revista de Derecho, Universidad Finis Terrae, $\mathrm{N}^{\circ} 3$ (1999), p. 233.

Verdugo, M., Pfeffer, E. y Nogueira, H., Derecho constitucional, T. I, Editorial Jurídica de Chile, Santiago, 2002.

Welzel, H., "Studien zum System des Strafrechts", en Welzel, H., Abhandlungen zum Strafrecht und zur Rechtsphilosophie, Walter de Gruyter, Berlin - New York, 1975.

Welzel, H., Derecho penal alemán (trad. Bustos y Yáñez), Editorial Jurídica de Chile, Santiago, 1970.

Zaffaroni, E. R., Alagia, A. y Slokar, A., Derecho penal. Parte general, Ediar, Buenos Aires, 2000.

Zapata, P., La jurisprudencia del Tribunal Constitucional, Universidad Andrés Bello, Santiago, 2002. 